\section{Battling against the inevitable}

Years of hitherto unsuccessful effort in the US Congress have culminated in a bill providing for an increase in research on earthquakes. Chris Sherwell reports from Washington

Developments now reaching a climax in Washington may not do for earthquake research what previous muchpublicised efforts did for space and cancer research, but the comparison may not be entirely inappropriate. The fanfares may be absent and the vistas uncertain, but an agreed commitment in principle which also has legislative form now promises a long-awaited boost for work in an exciting area and marks an important move from disaster relief to disaster prevention.

The latest step along the tortuous path to a comprehensive coordinated programme to reduce the hazards posed by earthquakes came last week when the House of Representatives approved by a margin of 229 votes to 125 an authorisation bill on which two House committees had reported. The bill was due to go back to the Senate late last week for consideration of the minor differences from the Senate version passed earlier this year, and was expected to find its way to President Carter's desk for signature shortly thereafter.

The bill, which when enacted will be known as the Earthquake Hazards Reduction Act of 1977, is designed to reduce the risks to life and property of future earthquakes in the United States. The logic underlying it is simple: earthquakes are inevitable, and population increases and urbanisation enhance the dangers they pose. To minimise both the risks and potential losses, a coordinated programme to increase research and to help apply its findings and generally improve the readiness of vulnerable areas for emergencies is necessary. The bill creates a \$215million three-year federal programme to do just that.

Though expenditure is scheduled to begin at the start of the coming financial year (fiscal year 1978) beginning on 1 October, the money must still be appropriated in a separate process. In the meantime the agencies slated to use it must rely on appropriations already granted them for that period. The two major agencies involved-the National Science Foundation (NSF) and the US Geological
Survey (USGS)-expect to feel the improvement over recent years quite soon, however, because the appropriations already granted are based largely on the same formulation used in drawing up the bill.

That formulation was contained in a report of a joint advisory committee chaired by Dr Nathan Newmark and published a year ago. Entitled Earthquake Prediction and Hazard Mitigation: Options for USGS and NSF programs, the report outlined low, intermediate and high levels of support for earthquake reseach, all of which were higher than funding levels in past years. The intermediate level, which President Ford used in his proposed budget for fiscal year 1978 and which President Carter retained in his revisions, provided for cxpenditure of nearly $\$ 54$ million, an increase from $\$ 22 \frac{1}{2}$ million the previous year. This was split approximately $52: 48$ between NSF and USGS (in favour of NSF). Under the bill passed by the House, some $\$ 55$ million would be split $50: 50$.

Going by the breakdowns given in the Newmark Report, the two agencies would each spend about $10 \%$ of their 1978 allocations on fundamental studies of the causes and mechanisms of earthquakes. NSF does not expect to see any great difference in this area, but on the engineering front, which

\title{
No long encounter with Halley's Comet
}

THE National Aeronautics and Space Administration (NASA) has reluctantly abandoned an ambitious and expensive plan to conduct a closerange study of Halley's Comet as it swings around the Sun in 1986. The plan would have entailed launching a spacecraft in 1982 on a complicated journey, culminating in an extended rendezvous with the comet three and a half years later.

According to NASA officials, development of the spacecraft together with a new propulsion system to manoeuvre it into Halley's orbit would have cost $\$ 500-600$ million. In particular, considerable outlays would have been needed in the next two years to make the 1982 launch date, and NASA simply doesn't have enough money in its budget.

Consequently, the agency has been forced to drop the idea of paying an extensive visit to Halley's Comet, and it is now looking into less expensive plans to launch a spacecraft to make a brief encounter with the comet soon after it emerges from behind the Sun. In addition, NASA is con- sidering the possibility of developing a spacecraft to make a lengthy visit to the comet Encke in 1987.

The decision to forego the chance of a long encounter with Halley's Comet will be a major disappointment to many space scientists. Comets have recently come under serious study because they may provide some clues to the origins of the universe. According to one widely-held theory, they are like giant dusty snowballs, made of condensed matter from outside the solar system. As they swing past the sun, heat vaporises material from the comet's nucleus, which then forms the so-called tail.

A trip to Halley's Comet, culminating in an extensive visit, would have been a difficult proposition, however. The chicf problem is that the comet orbits the Sun every 76 years in the opposite direction from the Earth, and a complicated series of manoeuvres would be required to bring a spacecraft to the same path and speed as the comet.

For the past year, NASA has been looking into two propulsion systems which could provide the required manoeuvres. The first, a so-called solar sail, would have consisted of an immense plastic sheet, deployed from the spacecraft on booms, which would act like a sail in the solar photon stream. The second idea, an ion drive system, would involve the ionisation of mercury vapour, which would then stream out of the back of the spacecraft to provide thrust. Last week, NASA announced that it has chosen the ion drive system which will be developed for a possible mission to visit Encke in 1987 and which will also be used to power future interplanetary probes.

Though the plan to rendezvous with Halley's comet has been abandoned, NASA may still launch a spacecraft in 1985 to fly close to the comet and pass through its tail. Such a mission would not require a special propulsion system because complicated manoeuvres will not be required to match orbits. It would consequently be much cheaper, but the scientific benefits would also be much less.

Colin Norman 